Received: 14 August 2017

Accepted: 5 October 2017

Published online: 19 October 2017

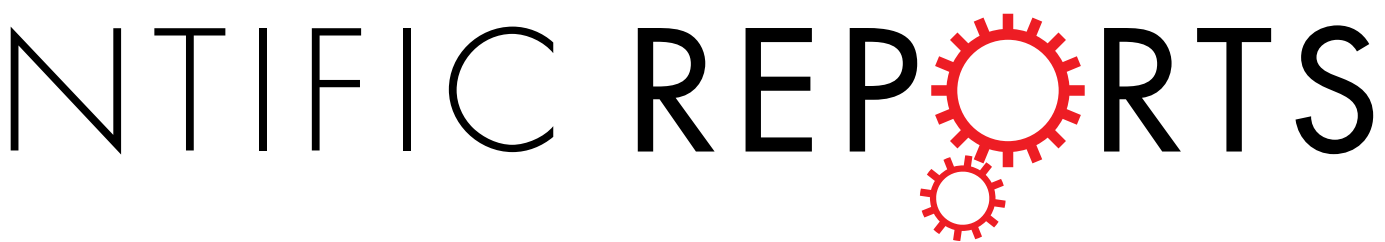

Porous nitrogen-enriched

carbonaceous material from marine

waste: chitosan-derived carbon

nitride catalyst for aerial oxidation of 5-hydroxymethylfurfural (HMF) to 2,5-furandicarboxylic acid

\author{
Sanny Verma ${ }^{1}$, Mallikarjuna N. Nadagouda ${ }^{2}$ \& Rajender S. Varma $\mathbb{1}^{2}$
}

Chitosan-derived, porous nitrogen-enriched carbonaceous carbon nitride catalyst $\left(\mathrm{PCN}_{\mathrm{x}}\right)$ has been synthesized from marine waste and its use demonstrated in a metal-free heterogeneous selective oxidation of 5-hydroxymethyl-furfural (HMF) to 2,5-furandicarboxylic acid (FDCA) using aerial oxygen under mild reaction conditions.

Growing demand for petroleum-derived products due to the waning reserves of fossil resources has prompted researchers to seriously consider the sustainable utilization of high-value chemicals and transportation fuels from readily available biomass resource ${ }^{1-6}$. 5-hydroxymethylfurfuryl (HMF) is one of the common but important platform chemical derived from carbohydrates and can be further upgraded to a variety of useful entities (Fig. 1) such as 2,5-furandicarboxylic acid (FDCA), 5-hydroxymethyl-2-furancarboxylic acid (HMFCA), 5-formyl-2-furancarboxylic acid (FFCA), maleic anhydride (MA) and 2,5-diformylfuran (DFF) ${ }^{7-11}$. Among these, FDCA is widely used entity of significant value deployed in the production of bio-based polymers namely polyethylene 2,5-furandicarboxylate (PEF) and fine chemicals ${ }^{12-14}$. Interestingly, FDCA can be considered a viable substitute for the petroleum-derived terephthalic acid, which is used as an essential molecule in the synthesis of polybutyleneterephthalate (PBT) and polyethylene terephthalate (PET) plastics ${ }^{15,16}$.

Earlier, HMF has been fully oxidized to FDCA using toxic oxidants such as nitric acid and potassium permanganate often in stoichiometric quantities generating copious amount of wastes ${ }^{17}$. Various metal-based homogeneous and heterogeneous catalytic systems have been reported in literature for the direct oxidation of HMF to FDCA $^{18-22}$. Among homogeneous catalysts, metal-bromide have been reported for the oxidation of $\mathrm{HMF}^{23-25}$. Yet, these catalysts are difficult to separate and frequently lead to the formation of inorganic wastes as by-products that result in environmental contamination. Heterogeneous catalysts such as Pd-, Pt-, and Au-based or bimetallic catalysts including earth abundant metal-based catalysts have also been explored for the synthesis of FDCA under aerobic conditions ${ }^{26-31}$. However, industrial applications of these metal-based heterogeneous catalysts has not been fruitful in view of higher catalyst cost and the leaching of metal ions into reaction systems making purification more difficult thus culminating in severe environmental pollution. Hence, the search and development of sustainable, cost-effective, metal-free, and efficient heterogeneous catalysts is actively pursued for the aerobic oxidation of HMF to FDCA.

Recently, Wu et al. observed the efficient oxidation of HMF to FDCA with yields of $80 \%$ using metal-free $\mathrm{N}$-doped nanoporous graphitic (NNC) catalyst at $80^{\circ} \mathrm{C}$ under aerobic condition ${ }^{32}$; catalyst was synthesized via the pyrolysis of zeolitic imidazole frameworks such as ZIF- 8 at $900^{\circ} \mathrm{C}$. However, this method requires catalyst preparation via circuitous route and extended reaction time. In continuous of our work towards the development

${ }^{1}$ Oak Ridge Institute for Science and Education, P. O. Box 117, Oak Ridge, TN, 37831, USA. ${ }^{2}$ Water Systems Division, Water Resources Recovery Branch, National Risk Management Research Laboratory, U. S. Environmental Protection Agency, 26 West Martin Luther King Drive, MS 443, Cincinnati, Ohio, 45268, USA. Correspondence and requests for materials should be addressed to R.S.V. (email: varma.rajender@epa.gov) 


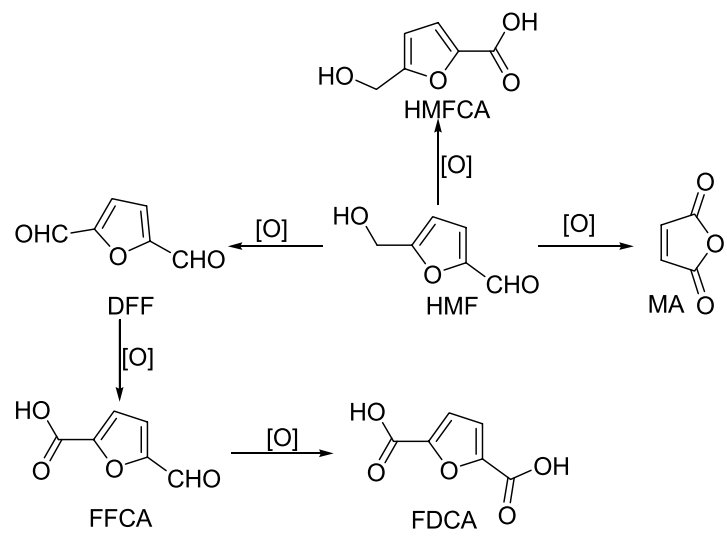

Figure 1. Oxidation products generated from 5-hydroxymethylfurfuryl (HMF).

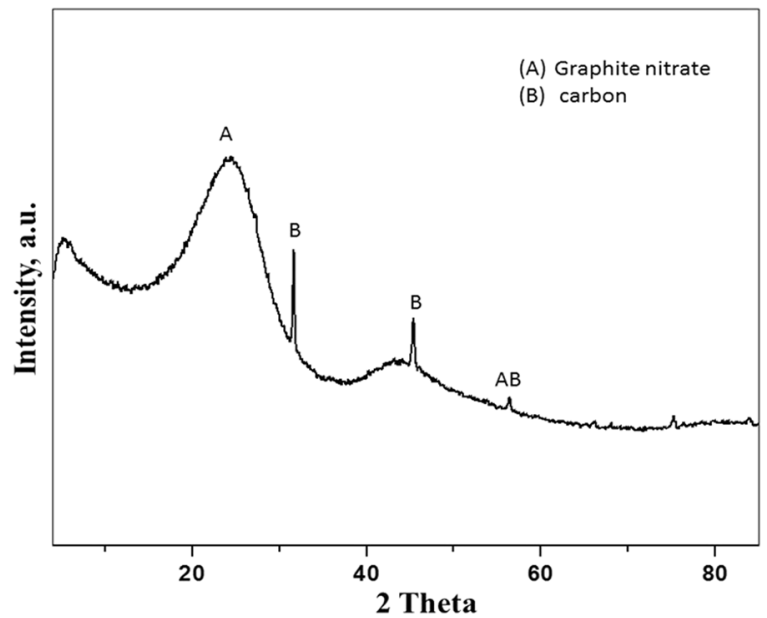

Figure 2. XRD analysis of $\mathrm{PCN}_{\mathrm{x}}$ catalyst.

of sustainable protocol in synthetic transformations ${ }^{33-39}$, herein, we report a metal-free, efficient method for the aerial oxidation of HMF to FDCA using marine waste originated chitosan-derived porous carbon nitride $\left(\mathrm{PCN}_{\mathrm{x}}\right)$ catalyst as a solid catalyst.

\section{Synthesis and Characterization of Catalyst}

The porous carbon nitride catalyst $\left(\mathrm{PCN}_{\mathrm{x}}\right)$ was synthesized via calcination of chitosan at $300^{\circ} \mathrm{C}$ for 4 hours under nitrogen atmosphere. The ensuing $\mathrm{PCN}_{\mathrm{x}}$ catalyst was characterized using X-ray diffraction (XRD), transmission electron microscope (TEM), and Brunauer-Emmett-Teller (BET) analysis. The XRD patterns of the PCN $\mathrm{Cat}_{\mathrm{x}}$ alyst show the characteristic pattern of graphitized carbon (Fig. 2). The graphitic line (002) of the $\mathrm{PCN}_{\mathrm{x}}$ catalyst was observed at the diffraction peak of $24.97^{\circ}$ corresponding to inter-layer spacing of about $0.345 \mathrm{~nm}$ which is usually attributed to a high degree of crystallinity of graphitic layers. This XRD pattern also reveals a low content of amorphous carbon and impurities. Additionally, the XRD diffraction peak of $24.97^{\circ}$ confirms the presence of glassy carbon known as graphite nitrate supports as described by Afolabi et al.$^{40}$. TEM analysis shows porous structure of $\mathrm{PCN}_{\mathrm{x}}$; wrinkles and bends are easily visible in Fig. 3 which are instigated by various defects. The porous nature of the material was further supported by BET surface area analysis and was found to be $92.83 \mathrm{~m}^{2} / \mathrm{g}$.

\section{Results and Discussion}

To study the feasibility for the catalytic aerial oxidation of 5-HMF to FDCA conversion (Fig. 4), different metal-free carbonaceous materials under basic conditions and varying temperature range were evaluated (Table 1, entries 1-22). Various carbon-based catalysts were examined namely graphite, graphene oxide (GO), carbon nanotubes (CNT), and carbon nanofibers (CNF) for the aerial oxidation of 5-HMF to FDCA using water as a solvent and $\mathrm{K}_{2} \mathrm{CO}_{3}$ as a base at different temperature (Table 1, entries 1-12); no FDCA production was discerned after 36 hours of reaction (Table 1, entries 1-12). It has been reported that the graphitic nitrogen activates oxygen and plays a central role in the aerobic oxidation of alcohols ${ }^{41}$. Consequently, we tested $\mathrm{N}$-doped carbon materials that contained graphitic nitrogen as shown in Table 1 (Table 1, entries 13-22). Nitrogen doped graphene gave $5 \%$ of FDCA after 36 hours (Table 1 , entry 15$)$ whereas graphitic carbon nitride $\left(\mathrm{g}-\mathrm{C}_{3} \mathrm{~N}_{4}\right)$ afforded only $8 \%$ and $15 \%$ yields of FDCA at $50^{\circ} \mathrm{C}$ and $70^{\circ} \mathrm{C}$, respectively (Table 1, entries 17-18). Nearly quantitative yield of 


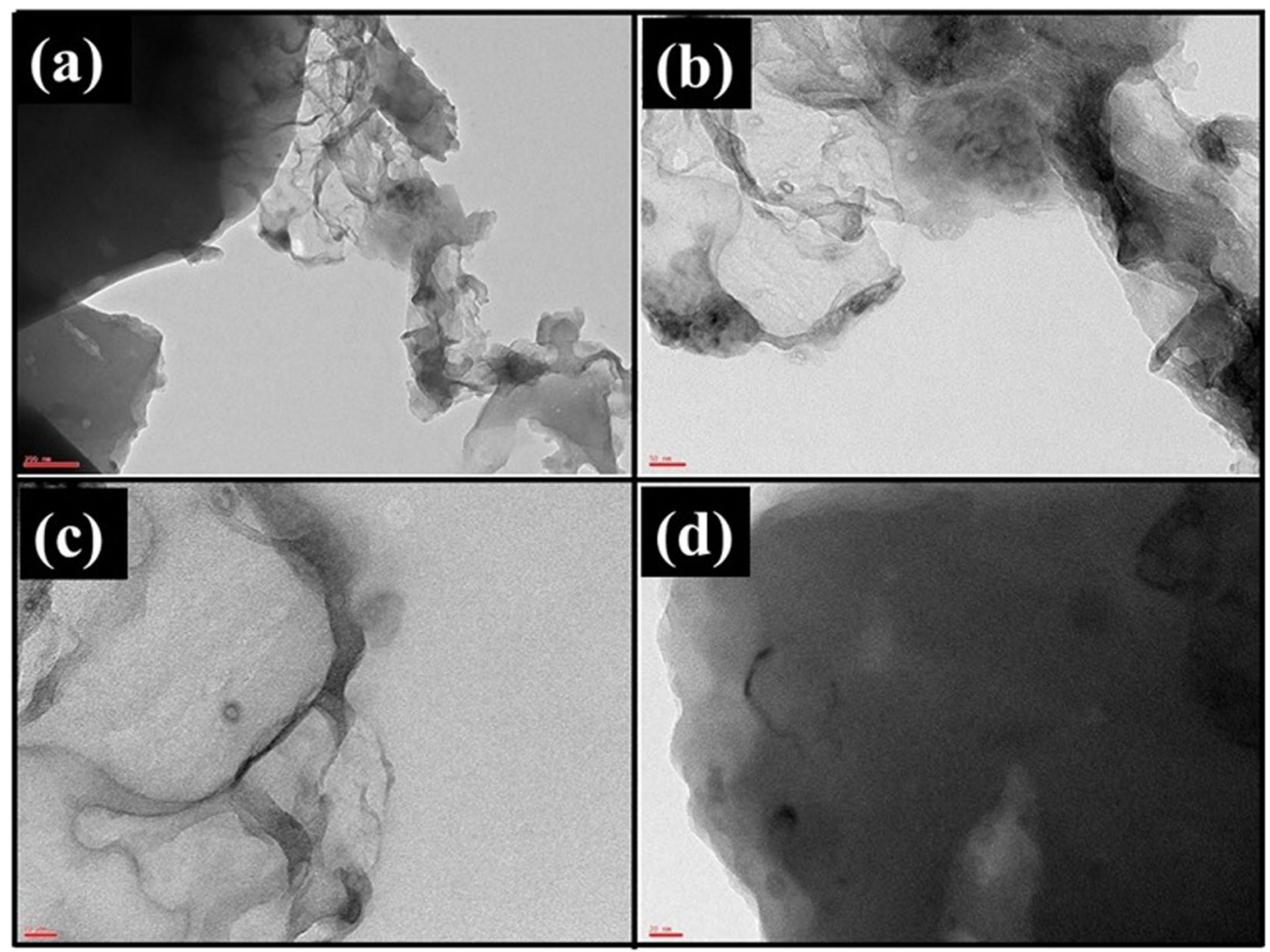

Figure 3. TEM analysis of $\mathrm{PCN}_{\mathrm{x}}$ catalyst.

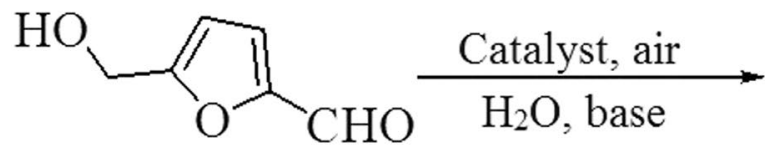

5-HMF<smiles>O=C(O)c1ccc(C(=O)O)o1</smiles>

FDCA

Figure 4. Oxidation of 5-HMF to FDCA.

FDCA, however, was obtained when $\mathrm{PCN}_{\mathrm{x}}$ was used as a catalyst (Table 1, entries 19-22); FDCA yields of 8\%, $46 \%, 83 \%$ were observed at $30^{\circ} \mathrm{C}, 50^{\circ} \mathrm{C}$ and $70^{\circ} \mathrm{C}$, respectively (Table 1 , entries 19-21). Notably, increasing the reaction temperature to $80^{\circ} \mathrm{C}$, did not give any further improvement in yield (Table 1, entry 22). Furthermore, to understand the effect of base on the reaction, different bases such as $\mathrm{NaOH}, \mathrm{KOH}, \mathrm{Na}_{2} \mathrm{CO}_{3}$ were also evaluated at $70^{\circ} \mathrm{C}$ (Table 1, entries 23-25). However, these bases failed to increase the product yield under aerial condition.

Recycling of chitosan-derived porous $\mathrm{CN}_{\mathrm{X}}$ catalyst for the aerial oxidation of 5-HMF to FDCA. A set of experiments were performed using 5-HMF in water. After the completion of each reaction, the $\mathrm{CN}_{\mathrm{X}}$ catalyst was recovered using membrane $(0.47 \mu \mathrm{m}$ pore size $)$ filter, washed with water and reused for the oxidation of a fresh batch of 5-HMF. The $\mathrm{CN}_{\mathrm{X}}$ catalyst could be recycled and reused up to five times without any loss in its activity (Fig. 5). The XRD analysis of the $\mathrm{CN}_{X}$ catalyst before and after the reaction confirms that there is no significant change in the pattern/morphology of the catalyst, which signifies high stability of $\mathrm{CN}_{\mathrm{X}}$ during the course of the reaction (Supporting Information).

\section{Conclusion}

We have developed an efficient, sustainable, cost-effective and metal-free protocol for the aerial oxidation of 5-HMF to FDCA using marine waste originated chitosan-derived porous CNx catalyst under mild reaction conditions. This highly active $\mathrm{PCNx}$ has been synthesized via calcination of the chitosan at $300^{\circ} \mathrm{C}$ under nitrogen atmosphere. The graphitic nitrogen in PCNx activates the oxygen and plays a key role in the aerobic oxidation of alcohols; the oxidation of 5-HMF to FDCA is accomplished in high yield (83\%) under ambient air pressure at $70^{\circ} \mathrm{C}$. The PCNx catalyst shows very good recyclability and no significant loss of activity has been observed up to the fifth run. 


\begin{tabular}{|c|c|c|c|c|}
\hline Entry & Catalyst & Time & Temperature & Yield $^{b}$ \\
\hline 1 & Graphite & $36 \mathrm{~h}$ & $30^{\circ} \mathrm{C}$ & - \\
\hline 2 & Graphite & $36 \mathrm{~h}$ & $50^{\circ} \mathrm{C}$ & - \\
\hline 3 & Graphite & $36 \mathrm{~h}$ & $70^{\circ} \mathrm{C}$ & - \\
\hline 4 & GO & $36 \mathrm{~h}$ & $30^{\circ} \mathrm{C}$ & - \\
\hline 5 & GO & $36 \mathrm{~h}$ & $50^{\circ} \mathrm{C}$ & - \\
\hline 6 & GO & $36 \mathrm{~h}$ & $70^{\circ} \mathrm{C}$ & - \\
\hline 7 & $\mathrm{CNT}$ & $36 \mathrm{~h}$ & $30^{\circ} \mathrm{C}$ & - \\
\hline 8 & CNT & $36 \mathrm{~h}$ & $50^{\circ} \mathrm{C}$ & - \\
\hline 9 & CNT & $36 \mathrm{~h}$ & $70^{\circ} \mathrm{C}$ & - \\
\hline 10 & $\mathrm{CNF}$ & $36 \mathrm{~h}$ & $30^{\circ} \mathrm{C}$ & - \\
\hline 11 & $\mathrm{CNF}$ & $36 \mathrm{~h}$ & $50^{\circ} \mathrm{C}$ & - \\
\hline 12 & $\mathrm{CNF}$ & $36 \mathrm{~h}$ & $70^{\circ} \mathrm{C}$ & - \\
\hline 13 & $N$-doped graphene & $36 \mathrm{~h}$ & $30^{\circ} \mathrm{C}$ & - \\
\hline 14 & $N$-doped graphene & $36 \mathrm{~h}$ & $50^{\circ} \mathrm{C}$ & traces \\
\hline 15 & $N$-doped graphene & $36 \mathrm{~h}$ & $70^{\circ} \mathrm{C}$ & $5 \%$ \\
\hline 16 & g- $\mathrm{C}_{3} \mathrm{~N}_{4}$ & $36 \mathrm{~h}$ & $30^{\circ} \mathrm{C}$ & - \\
\hline 17 & g- $\mathrm{C}_{3} \mathrm{~N}_{4}$ & $36 \mathrm{~h}$ & $50^{\circ} \mathrm{C}$ & $8 \%$ \\
\hline 18 & g- $\mathrm{C}_{3} \mathrm{~N}_{4}$ & $36 \mathrm{~h}$ & $70^{\circ} \mathrm{C}$ & $15 \%$ \\
\hline 19 & $\mathrm{PCN}_{\mathrm{x}}$ & $36 \mathrm{~h}$ & $30^{\circ} \mathrm{C}$ & $8 \%$ \\
\hline 20 & $\mathrm{PCN}_{\mathrm{x}}$ & $36 \mathrm{~h}$ & $50^{\circ} \mathrm{C}$ & $46 \%$ \\
\hline 21 & $\mathrm{PCN}_{\mathrm{x}}$ & $36 \mathrm{~h}$ & $70^{\circ} \mathrm{C}$ & $83 \%$ \\
\hline 22 & $\mathrm{PCN}_{\mathrm{x}}$ & $48 \mathrm{~h}$ & $80^{\circ} \mathrm{C}$ & $83 \%$ \\
\hline $23^{c}$ & $\mathrm{PCN}_{\mathrm{x}}$ & $36 \mathrm{~h}$ & $70^{\circ} \mathrm{C}$ & $79 \%$ \\
\hline $24^{\mathrm{d}}$ & $\mathrm{PCN}_{\mathrm{x}}$ & $36 \mathrm{~h}$ & $70^{\circ} \mathrm{C}$ & $80 \%$ \\
\hline $25^{\mathrm{e}}$ & $\mathrm{PCN}_{\mathrm{x}}$ & $36 \mathrm{~h}$ & $70^{\circ} \mathrm{C}$ & $77 \%$ \\
\hline
\end{tabular}

Table 1. Screening of catalysts and reaction optimization for FDCA conversion ${ }^{\mathrm{a}}$. a) Reaction condition: 5-HMF $(1.0 \mathrm{mmol})$, water $(10.0 \mathrm{ml}), \mathrm{PCN}_{\mathrm{x}}(20 \mathrm{mg}), \mathrm{K}_{2} \mathrm{CO}_{3}(1.0 \mathrm{mmol})$; b) Isolated yield; c) $\mathrm{NaOH}(1.0 \mathrm{mmol})$; $) \mathrm{KOH}$ (1.0 mmol); e) $\mathrm{Na}_{2} \mathrm{CO}_{3}(1.0 \mathrm{mmol})$.

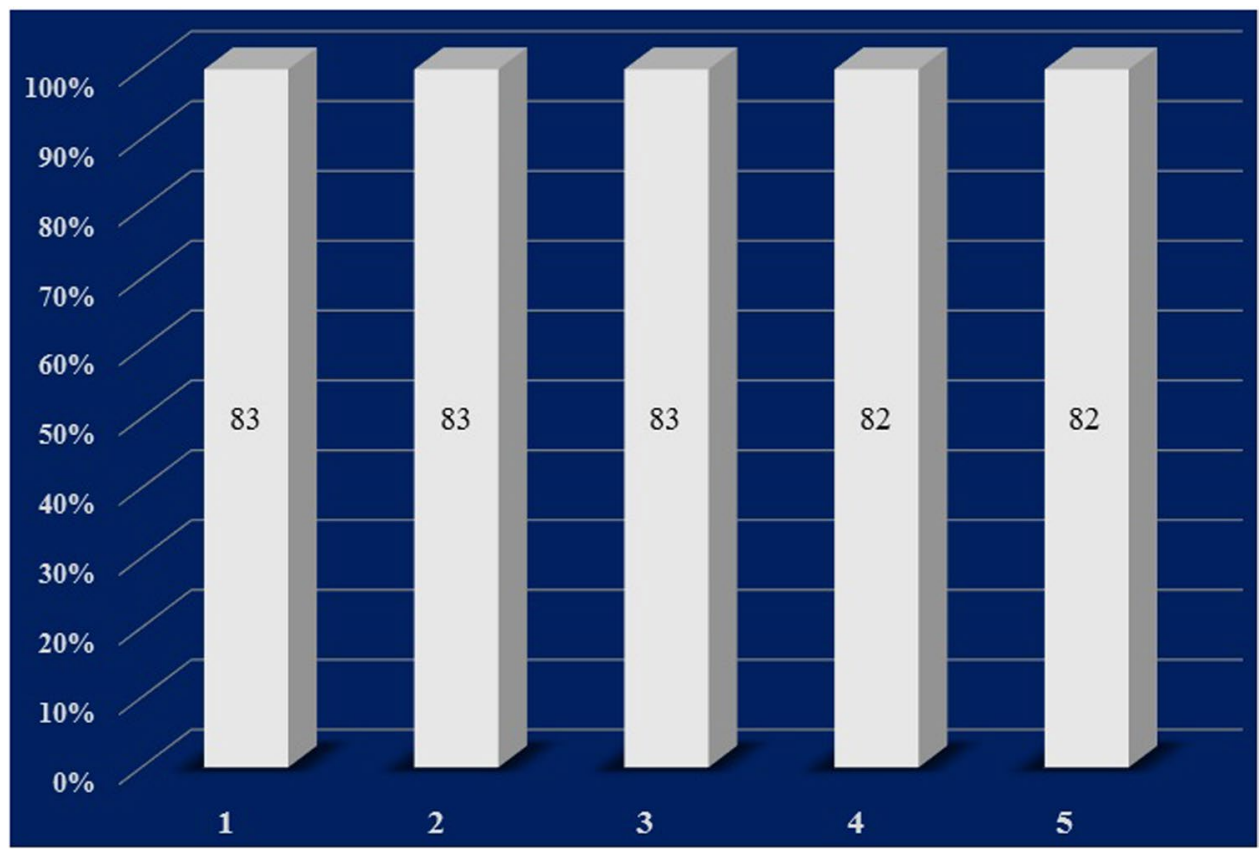

Figure 5. Recycling of chitosan derived porous $\mathrm{CN}_{\mathrm{X}}$ catalyst.

Disclaimer. The views expressed in this article are those of the authors and do not necessarily represent the views or policies of the U.S. Environmental Protection Agency. Any mention of trade names or commercial products does not constitute endorsement or recommendation for use. 


\section{References}

1. Sen, S. M. et al. A sulfuric acid management strategy for the production of liquid hydrocarbon fuels via catalytic conversion of biomass-derived levulinic acid. Energy Environ. Sci. 5, 9690-9697 (2012).

2. Wang, Y., Liu, B., Huang, K. \& Zhang, Z. Aerobic oxidation of biomass-derived 5-(Hydroxymethyl)furfural into 2,5-diformylfuran catalyzed by the trimetallic mixed oxide (Co-Ce-Ru). Ind. Eng. Chem. Res. 53, 1313-1319 (2014).

3. Bozell, J. J. \& Petersen, G. R. Technology development for the production of bio-based products from bio-refinery carbohydrates-the US Department of Energy's “Top 10” revisited. Green Chem. 12, 539-554 (2010).

4. Chheda, J. N., Huber, G. W. \& Dumesic, J. A. Liquid-phase catalytic processing of biomass-derived oxygenated hydrocarbons to fuels and chemicals. Angew. Chem., Int. Ed. 46, 7164-7183 (2007).

5. An, D. et al. Selective conversion of cellobiose and cellulose into gluconic acid in water in the presence of oxygen, catalyzed by polyoxometalate-supported gold nanoparticles. Chem. Eur. J. 18, 2938-2947 (2012).

6. Serrano-Ruiz, J. C., Luque, R. \& Sepúlveda-Escribano, A. Transformations of biomass-derived platform molecules: from high added-value chemicals to fuels via aqueous-phase processing. Chem. Soc. Rev. 40, 5266-5281 (2011).

7. Putten, R. V. et al. Hydroxymethylfurfural, a versatile platform chemical made from renewable resources. Chem. Rev. 113, 1499-1597 (2013).

8. Choudhary, V. et al. Insights into the interplay of Lewis and Brønsted acid catalysts in glucose and fructose conversion to 5-(Hydroxymethyl)furfural and levulinic acid in aqueous media. J. Am. Chem. Soc. 135, 3997-4006 (2013).

9. Corma, A., Iborra, S. \& Velty, A. Chemical routes for the transformation of biomass into chemicals. Chem. Rev. 107, 2411-2502 (2007).

10. Deng, L. et al. Catalytic conversion of biomass-derived carbohydrates into gamma-valerolactone without using an external $\mathrm{H}_{2}$ supply. Angew. Chem., Int. Ed. 48, 6529-6532 (2009).

11. Yi, G., Teong, S. P., Li, X. \& Zhang, Y. Purification of biomass-derived 5-hydroxymethylfurfural and its catalytic conversion to 2,5-furandicarboxylic acid. ChemSusChem 7, 2131-2135 (2014).

12. Eerhart, A. J. J. E. et al. Fuels and plastics from lignocellulosic biomass via the furan pathway; a technical analysis. RSC Adv. 4, 3536-3549 (2014).

13. Ma, J. et al. The copolymerization reactivity of diols with 2,5-furandicarboxylic acid for furan-based copolyester materials. J. Mater. Chem. 22, 3457-3481 (2012).

14. Eerhart, A. J. J. E., Faaij, A. P. C. \& Patel, M. K. Replacing fossil based PET with biobased PEF; process analysis, energy and GHG balance. Energy Environ. Sci. 5, 6407-6422 (2012).

15. Dutta, S., De, S. \& Saha, B. A brief summary of the synthesis of polyester building-block chemicals and biofuels from 5-hydroxymethylfurfural. ChemPlusChem 77, 259-272 (2012).

16. Zhu, Y., Romain, C. \& Williams, C. K. Sustainable polymers from renewable resources. Nature 540, 354-362 (2016).

17. Toshinari, M., Hirokazu, K., Takenobu, K. \& Hirohide, M. Method for producing furan-2,5-dicarboxylic acid. U.S. Patent 7,411,078 (2008).

18. Ma, J., Du, Z., Xu, J., Chu, Q. \& Pang, Y. Efficient aerobic oxidation of 5-hydroxymethylfurfural to 2,5-diformylfuran, and synthesis of a fluorescent material. ChemSusChem 4, 51-54 (2011).

19. Casanova, O., Iborra, S. \& Corma, A. Biomass into chemicals: aerobic oxidation of 5-hydroxymethyl-2-furfural into 2,5-furandicarboxylic acid with gold nanoparticle catalysts. ChemSusChem 2, 1138-1144 (2009).

20. Carlini, C. et al. Selective oxidation of 5-hydroxymethyl-2-furaldehyde to furan-2,5-dicarboxaldehyde by catalytic systems based on vanadyl phosphate. Appl. Catal., A 289, 197-204 (2005).

21. Davis, S. E. et al. Oxidation of 5-hydroxymethylfurfural over supported Pt, Pd and Au catalysts. Catal. Today 160, 55-60 (2011).

22. Gorbanev, Y. Y. et al. Gold-catalyzed aerobic oxidation of 5-hydroxymethylfurfural in water at ambient temperature. ChemSusChem 2, 672-675 (2009).

23. Partenheimer, W. \& Grushin, V. V. Synthesis of 2,5-diformylfuran and furan-2,5-dicarboxylic acid by catalytic air-oxidation of 5 -hydroxymethylfurfural. unexpectedly selective aerobic oxidation of benzyl alcohol to benzaldehyde with metal $=$ bromide Catalysts. Adv. Synth. Catal. 343, 102-111 (2001).

24. Saha, B., Dutta, S. \& Abu-Omar, M. M. Aerobic oxidation of 5-hydroxylmethylfurfural with homogeneous and nanoparticulate catalysts. Catal. Sci. Technol. 2, 79-81 (2012).

25. Zuo, X., Venkitasubramanian, P., Busch, D. H. \& Subramaniam, B. Optimization of Co/Mn/Br-catalyzed oxidation of 5-hydroxymethylfurfural to enhance 2, 5-furandicarboxylic acid yield and minimize substrate burning. ACS Sustainable Chem. Eng. 4,3659-3668 (2016).

26. Mittal, N. et al. One-pot synthesis of 2, 5-diformylfuran from fructose using a magnetic bi-functional catalyst. RSC Adv. 6, 25678-25688 (2016).

27. Sádaba, I. et al. Catalytic performance of zeolite-supported vanadia in the aerobic oxidation of 5-hydroxymethylfurfural to 2,5-diformylfuran. Chem CatChem 5, 284-293 (2013).

28. Le, N.-T. et al. Selective oxidation of 5-hydroxymethyl-2-furfural into 2,5-diformylfuran over $\mathrm{VO}^{2+}$ and $\mathrm{Cu}^{2+}$ ions immobilized on sulfonated carbon catalysts. Appl. Catal., A 464-465, 305-312 (2013).

29. Chen, J. et al. One-step approach to 2,5-diformylfuran from fructose by proton- and vanadium-containing graphitic carbon nitride. Chem CatChem 6, 3174-3181 (2014).

30. Ghezali, W. et al. choline chloride/DMSO solvent for the direct synthesis of diformylfuran from carbohydrates in the presence of heteropolyacids. Green Chem. 17, 4459-4464 (2015).

31. Gupta, N. K., Nishimura, S., Takagaki, A. \& Ebitani, K. Hydrotalcite-supported gold-nanoparticle-catalyzed highly efficient basefree aqueous oxidation of 5-hydroxymethylfurfural into 2, 5-furandicarboxylic acid under atmospheric oxygen pressure. Green Chem. 13, 824-827 (2011).

32. Nguyen, C. V. et al. A metal-free, high nitrogen-doped nanoporous graphitic carbon catalyst for an effective aerobic HMF-to-FDCA conversion. Green Chem. 18, 5957-5961 (2016).

33. Jorge, E. Y. C. et al. Metal-exchanged magnetic $\beta$-zeolites: valorization of lignocellulosic biomass-derived compounds to platform chemicals. Green Chem. 19, 3856-3868 (2017).

34. Lima, T. M. et al. Magnetic ZSM-5 zeolite: a selective catalyst for the valorization of furfuryl alcohol to $\gamma$-valerolactone, alkyl levulinates or levulinic acid. Green Chem. 18, 5586-5593 (2016).

35. Tadele, K., Verma, S., Gonzalez, M. A. \& Varma, R. S. A sustainable approach to empower the bio-based future: upgrading of biomass via process intensification. Green Chem. 19, 1624-1627 (2017).

36. Verma, S. et al. Sustainable pathway to furanics from biomass via heterogeneous organo-catalysis. Green Chem. 19, 164-168 (2017).

37. Verma, S., Baig, R. B., Nadagouda, M. N. \& Varma, R. S. Sustainable strategy utilizing biomass: visible-light-mediated synthesis of $\gamma$-valerolactone. Chem CatChem 8, 690-693 (2016).

38. Verma, S., Baig, R. B., Nadagouda, M. N. \& Varma, R. S. Visible light mediated upgrading of biomass to biofuel. Green Chem. 18, 1327-1331 (2016).

39. Varma, R. S. Greener and sustainable trends in synthesis of organics and nanomaterials. ACS Sustainable Chem. Eng. 4, 5866-5878 (2016).

40. Afolabi, A. S., Abdulkareem, A. S., Iyuke, S. E. \& van Zyl Pienaar, H. C. Continuous production of carbon nanotubes and diamond films by swirled floating catalyst chemical vapour deposition method. S. Afr. J. Sci. 105, 278-281 (2009).

41. Watanabe, H. et al. Nitrogen-doped, metal-free activated carbon catalysts for aerobic oxidation of alcohols. ACS Catal. 5, 2886-2894 (2015). 


\section{Acknowledgements}

SV was supported by the Postgraduate Research Program at the National Risk Management Research Laboratory administered by the Oak Ridge Institute for Science and Education through an interagency agreement between the U.S. Department of Energy and the U.S. Environmental Protection Agency.

\section{Author Contributions}

S.V. designed and conducted experiments and performed data analysis. S.V., M.N.N. and R.S.V. wrote the manuscript. All authors reviewed the manuscript.

\section{Additional Information}

Supplementary information accompanies this paper at https://doi.org/10.1038/s41598-017-14016-5.

Competing Interests: The authors declare that they have no competing interests.

Publisher's note: Springer Nature remains neutral with regard to jurisdictional claims in published maps and institutional affiliations.

(c) Open Access This article is licensed under a Creative Commons Attribution 4.0 International License, which permits use, sharing, adaptation, distribution and reproduction in any medium or format, as long as you give appropriate credit to the original author(s) and the source, provide a link to the Creative Commons license, and indicate if changes were made. The images or other third party material in this article are included in the article's Creative Commons license, unless indicated otherwise in a credit line to the material. If material is not included in the article's Creative Commons license and your intended use is not permitted by statutory regulation or exceeds the permitted use, you will need to obtain permission directly from the copyright holder. To view a copy of this license, visit http://creativecommons.org/licenses/by/4.0/.

(C) The Author(s) 2017 